\title{
Experimental and kinetic modeling study of the pyrolysis and oxidation of diethylamine
}

\author{
Cato A.R. Pappijna, Nicolas Vinb, Florence H. Vermeirea, Ruben Van de Vijvera, \\ Olivier Herbinetb, Frédérique Battin-Leclerc ${ }^{b}$, Marie-Françoise Reyniers ${ }^{a}$, Guy B. \\ Marina, Kevin M. Van Geema
}

a Laboratory for Chemical Technology, Ghent University, Technologiepark 125, 9052 Gent, Belgium

${ }^{b}$ Laboratoire Réactions et Génie des Procédés, CNRS, Université de Lorraine, Nancy, France

Published in Fuel (2020) 175, 117744
https://doi.org/10.1016/j.fuel.2020.117744

\section{Highlights}

- First detailed experimental datasets for diethylamine pyrolysis and oxidation.

- Ab initio derived thermochemistry and kinetics for nitrogen species and reactions.

- Accurate kinetic model with only elementary steps.

- Identification of dominant pathways for the formation of hydrogen cyanide and $\mathrm{NO}_{\mathrm{x}}$.

\begin{abstract}
The pyrolysis and oxidation chemistry of diethylamine (DEA), a nitrogen-containing bio-oil model compound, is investigated theoretically and experimentally at low to intermediate temperatures. The pyrolysis of DEA is studied using two experimental units, i.e. a jet-stirred reactor and a tubular reactor. Oxidation experiments are performed at three different equivalence ratios, i.e. $\varphi=1.0$, 2.0 and 0.5 in the jet-stirred reactor unit. The temperature ranges from $500 \mathrm{~K}$ to $1100 \mathrm{~K}$, at a pressure of 1.07 bar, and with a space time of $2 \mathrm{~s}$. An elementary step kinetic model for DEA pyrolysis and oxidation is built using the automatic kinetic model generator Genesys with a base mechanism extracted from Glarborg et al. (2019) which describes the oxidation of the small nitrogen-containing species. Important thermodynamic and kinetic parameters for the DEA decomposition chemistry are obtained from quantum chemical calculations. The experimental trends are well predicted by the model, even without any fitting of the model thermodynamic or kinetic parameters. Rate of production analyses reveal the important pathways for the pyrolysis and low- and intermediate-temperature oxidation to hydrogen cyanide, acetonitrile, $\mathrm{NO}_{\mathrm{x}}$ and others.
\end{abstract}

Keywords: Diethylamine, Jet-stirred reactor, Pyrolysis, Low- and intermediate-temperature oxidation, Automatic kinetic modeling, Ab initio, 


\section{Introduction}

Untreated bio-oils produced by biomass fast pyrolysis contain substantial amounts of nitrogencontaining compounds [1,2]. The decomposition of these species is known to lead to the formation of small nitrogen-containing pollutants, such as hydrogen cyanide and ammonia, as well as $\mathrm{NO}_{\mathrm{x}}$ emissions, which has detrimental effects on the environment (e.g. acid rain, formation of groundlevel ozone). In order to minimize the emission of these toxic compounds, it is essential to gain insight into the reactions governing the conversion of fuel-bound nitrogen so that compound specific maximum allowable quantities can be defined in fuel standards. For example, $\mathrm{NO}_{\mathrm{x}}$ emissions from modern furnaces are limited to ppm's, and to predict these quantities reliably, an in-depth investigation of the pyrolysis and oxidation chemistry of nitrogen-containing species is needed $[3,4]$. To gain more insight into the nitrogen conversion, experimental and theoretical studies have focused on different classes of nitrogen-containing compounds, including amino acids [5,6] and heterocyclic structures, such as pyridine [7-11] and pyrrole [12-16]. Another important class of nitrogen-containing species is amines, i.e. compounds which are derivatives of ammonia by replacing one or more hydrogen atoms by a substituent such as an alkyl group. The conversion of these amines can lead to the formation of $\mathrm{NO}_{\mathrm{x}}$, even more so compared to nitrogencontaining aromatic compounds [17-19]. Thus, even though they are present in bio-oils only in small quantities (a few percent), their conversion should be studied in depth. While both the pyrolysis and oxidation of ammonia have been extensively investigated in the past [20-23], studies on the pyrolysis and oxidation chemistry of aliphatic amines are rather scarce. Some attention has been paid to the decomposition of the simplest primary amine, i.e. methylamine. Kantak et al. [24] studied the oxidation of methylamine experimentally in a flow reactor over the temperature range $600-1400 \mathrm{~K}$ at pressures of 0.01 and 1.01 bar. They constructed a reaction mechanism to describe the methylamine conversion under the studied conditions. Votsmeier et al. [25] also investigated the decomposition of methylamine with $\mathrm{NH}_{2}$ radicals in a shock tube over the temperature range $1600-2100 \mathrm{~K}$ at a pressure of 1.62 bar. They used the mechanism of Dean et al. [4] for the simulation of their experimental results. Lucassen et al. [26] investigated lean and rich flames of the two smallest isomeric amines dimethylamine and ethylamine and developed a kinetic model to simulate the experimental results. The thermodynamic parameters for several selected amine species were determined from quantum chemical calculations, while the kinetic parameters for the reactions of $\mathrm{C}_{2}$ hydrocarbon amines were approximated by analogy with the corresponding reactions of hydrocarbons, methylamine and ethanol. They conclude that there is a significant difference between the decomposition chemistry of the better understood oxygenates ethanol and dimethyl ether and the analogous nitrogen-containing compounds ethylamine and dimethylamine. Li et al. [27] studied the pyrolysis and oxidation of ethylamine in a shock tube over the temperature range $1200-1448 \mathrm{~K}$ at pressures of $0.86,1.37$ and 2.03 bar. They made some changes to the model of Li et al. to simulate the ignition delay times and $\mathrm{NH}_{2}$ and $\mathrm{OH}$ time-history measurements. Overall, it can be concluded that the experimental database for the combustion chemistry of the aliphatic amines needs to be augmented and kinetic models need to be developed with a higher level of detail.

Diethylamine has been chosen in this work as a representative model compound of secondary amine species present in bio-oils. The pyrolysis and oxidation chemistry of diethylamine (DEA) is studied - for the first time - both experimentally and theoretically through simulations with a newly developed kinetic model. Pyrolysis experiments are performed using two different experimental units: a jet-stirred reactor and a tubular reactor. Oxidation experiments are carried 
out using a jet-stirred reactor. The temperatures range from 500 to $1100 \mathrm{~K}$, at a pressure of 1.07 bar and both pyrolysis as well as oxidation at three different equivalence ratios are studied $(\varphi=$ 1.0, 2.0 and 0.5) with an DEA inlet mole fraction of 0.01. The newly developed model includes ab initio calculated thermodynamic and kinetic parameters for the key species and reactions at the CBS-QB3 level of theory. The DEA specific chemistry in the elementary step kinetic model is constructed with the automatic kinetic model generator Genesys [28]. The model of Glarborg et al. [29] is used to describe the oxidation of the small nitrogen-containing species not related to DEA. Rate of production analyses are performed at $700 \mathrm{~K}$ and $900 \mathrm{~K}$ to study the difference between the dominating pathways under varying pyrolysis and oxidation conditions.

\section{Experimental methods}

The pyrolysis and oxidation of DEA are studied experimentally using two different units: a jet-stirred reactor (JSR) and a tubular reactor (TR). The main features of both experimental units are discussed below, details can be found elsewhere for the JSR [30] and the TR [31].

In the JSR, the diluent and the liquid fuel are mixed and passed through an evaporator. For the oxidation experiments, oxygen is added to the gaseous flow downstream. The gaseous mixture passes through an annular preheating zone, where it is heated to the reactor temperature, and enters the jet-stirred reactor through four nozzles. The gas residence time inside the annular preheater is very short compared to the residence time inside the reactor, i.e. approximately $1 \%$ of the residence time in the JSR. Therefore, the reactivity in this zone can be neglected. The nozzles and reactor are designed to limit temperature and concentration gradients inside the reactor. Thermocoax resistance wires provide heating for the annular preheating zone and the reactor. A type $\mathrm{K}$ thermocouple, for which the calibrated accuracy as reported by the manufacturer is \pm 2.2

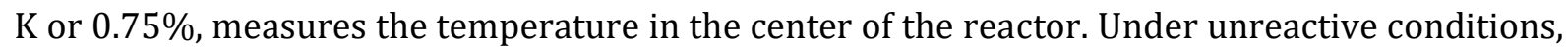
the temperature gradients in the reactor are below $5 \mathrm{~K}$. The temperature gradients have not been measured under reactive conditions. However, because of the perfect macro mixing obtained in the JSR and high dilution, i.e. 0.01 mole fraction of DEA, these temperature gradients are not expected to be significantly different from those under unreactive conditions. The pressure is set with a needle valve downstream of the reactor. The reactor has a fixed volume of $85 \mathrm{~cm}^{3}$.

The TR consists of a horizontal $60 \mathrm{~cm}$ long alumina tube (volume of $294 \mathrm{~cm}^{3}$ ) with an inner diameter of $2.0 \mathrm{~cm}$ and an outer diameter of $2.5 \mathrm{~cm}$. The tubular reactor is heated by an electrical furnace from Vecstar equipped with an S-type thermocouple. For each reaction set temperature, a temperature profile, i.e. temperature as a function of axial position in the TR, is measured in the absence of reaction using an R-type thermocouple, for which the calibrated accuracy as reported by the manufacturer is $\pm 1.5 \mathrm{~K}$ or $0.25 \%$. These temperature profiles are available in the Supporting Information. Under unreactive conditions, the temperature gradients in the reactor are below $5 \mathrm{~K}$. Because of the high dilution, i.e. 0.01 mole fraction of DEA, these temperature gradients are not expected to be significantly different under reactive conditions. For simulations, it can be assumed that the TR can be modeled as an ideal plug flow reactor [31].

The studied temperatures range from 500 to $1000 \mathrm{~K}$ for pyrolysis and to $1100 \mathrm{~K}$ for oxidation, with increments of $25 \mathrm{~K}$, to cover the complete fuel conversion range. The pressure is kept constant at 1.07 bar. The inlet mole fraction of DEA is set to 0.01 in the JSR and TR for all experimental conditions. The volumetric flow rate in the JSR, calculated with the total molar inlet 
flow rate and the temperature and pressure in the reactor, is $4.0610^{-5} \mathrm{~m}^{3} \mathrm{~s}^{-1}$, corresponding to an average residence time (or space time) of $2 \mathrm{~s}$. In the TR, the volumetric flow rate, calculated with the total inlet molar flow rate and the temperature and pressure setpoint reached in the central zone of the reactor, is equal to $2.5110^{-5} \mathrm{~m}^{3} \mathrm{~s}^{-1}$, corresponding to a space time of $2 \mathrm{~s}$. Helium, argon, oxygen are provided by Messer (purity of 99.99\%) and the nitrogen-containing compound DEA (purity $\geq 99.5 \%$ ) is purchased from Sigma-Aldrich. The gaseous flow rates are controlled by mass flow controllers (Bronkhorst) and the liquid fuel mass flow rate is regulated by a liquid-Coriolis-flow controller (Bronkhorst).

In both experimental units, the products are analyzed using four different analytical techniques. The reactor outlet is connected to different gas chromatographs (GC), which enable online quantification of the product species. The connection with the GC's is done via heated transfer lines, kept at $433 \mathrm{~K}$, to avoid product condensation. The first GC contains a Carbosphere packed column and a thermal conductivity detector (TCD). This GC is used to detect $\mathrm{H}_{2}, \mathrm{O}_{2}, \mathrm{~N}_{2}, \mathrm{CO}, \mathrm{CO}_{2}$, and $\mathrm{CH}_{4}$. The carrier gas is He, except for the detection of $\mathrm{H}_{2}$, for which $\mathrm{Ar}$ is used. The second GC is equipped with a PLOT-Q capillary column and a flame ionization detector (FID) preceded by a methanizer. The methanizer enables the detection and quantification of small oxygenates with the FID. The third gas chromatograph has a HP-5 ms capillary column coupled to an FID. This GC is used to detect the main carbon- and nitrogen-containing products with more than 5 non-hydrogen atoms. The three preceding gas chromatographs are used for the analysis of species from the JSR. Two other gas chromatographs are used for the detection of species from the TR. The first is identical to the one used to detect the main carbon- and nitrogen-containing products with more than 5 non-hydrogen atoms from the JSR. The other one is equipped with a PLOT-Q capillary column, a thermal conductivity detector (TCD) and a flame ionization detector (both detectors are installed in series). To enable on- or offline product identification, the reactor outlet is connected to a fourth gas chromatograph, which is equipped with either a PLOT-Q or HP-5 ms capillary column, and has a quadrupole mass spectrometer as detector. The GC carrier gas is helium. A chemiluminescence $\mathrm{NO}_{\mathrm{x}}$ analyzer (Thermo Scientific Model 42i) is adopted to measure the concentration of $\mathrm{NO}$ and $\mathrm{NO}_{2}$. The quantitative range is $0-5000 \mathrm{ppm}$ for $\mathrm{NO}$ and $0-500 \mathrm{ppm}$ for $\mathrm{NO}_{2}$. A Fourier Transform InfraRed spectrometer (FTIR) from Thermo Scientific Antaris equipped with a Mercure Cadmium Telluride photoelectric detector is used to obtain a second quantification of $\mathrm{NO}, \mathrm{NO}_{2}, \mathrm{DEA}$ and $\mathrm{HCN}$. The complete analysis section allows identification and quantification of all oxidation and pyrolysis products ranging from the smallest hydrocarbons, oxygenates and nitrogen-containing compounds up to products with 9 non-hydrogen atoms.

The pyrolysis of DEA is studied both with the JSR and TR. For oxidation, three different equivalence ratios, i.e. $\varphi=1.0,2.0$ and 0.5 , are studied with the JSR. In total, 32 species are identified and quantified for pyrolyis and oxidation using the described analytical techniques.

The carbon and nitrogen balances are closed within 5\% and all product yields are provided in Supporting Information. Because the configuration of the analysis section does not allow the quantification of water and hydrogen peroxide, the hydrogen and oxygen elemental balances are not available at oxidation conditions. The relative uncertainty on the experimental mole fraction is $5 \%$ for species calibrated using standards and $10 \%$ for species calibrated with the effective carbon number method, except for FTIR measurement for which the relative uncertainty can be estimated as $5 \%$. 


\section{Computational method}

Quantum chemical calculations are carried out with the high-performance supercomputer available at Ghent University at the CBS-QB3 level of theory [32] as implemented in Gaussian 09 [33]. In-house developed algorithms are used to perform an automatic search of the lowest energy conformer at the B3LYP/6-31G(d) level of theory [34]. From the CBS-QB3 results, the thermodynamic parameters of both species and transitions states, i.e. the standard enthalpy of formation, the standard intrinsic entropy and the heat capacities at different temperatures, are calculated using ideal gas statistical thermodynamics. Internal modes are treated as harmonic oscillators, except for modes which resemble rotations around single bonds. These internal modes are treated as 1-dimensional internal rotors, as long as the barrier does not exceed $50 \mathrm{~kJ} \mathrm{~mol}-1$. The hindrance potentials are determined at the B3LYP/6-31G(d) level of theory with (semi-) relaxed surface scans in which all coordinates, except for the dihedral angle of interest, are reoptimized at each scan angle with a step size of $10^{\circ}$. The Fourier series expression of the hindrance potential together with the reduced moment of inertia calculated at the $I^{(2,3)}$ level, as defined by East and Radom [35], are used to construct the Schrödinger equation for 1-dimensional internal rotation. With the eigenvalues of the solution the partition function is determined as a function of temperature. The thermodynamic data is calculated from the total partition function taking into account the symmetry and the number of optical isomers. For the calculation of the enthalpy of formation, the atomization method is applied. Two corrections are used to improve the accuracy of the enthalpy of formation calculated at the CBS-QB3 level of theory: spin-orbit corrections (SOC) [36], as these are not part of the CBS-QB3 methodology, and bond additive corrections (BAC) to correct systematic errors [37]. In case only relative enthalpies are required, i.e. for calculation of the rate coefficients and construction of a potential energy surface, these SOC and BAC corrections are not applied. The conventional transition state theory is used to calculate the rate coefficients over a temperature range of 300 to $1500 \mathrm{~K}$, with the asymmetric Eckart potential to account for tunneling [38]. The Arrhenius parameters are obtained by regression of the rate coefficients over the same temperature range. Using this methodology, the ab initio calculated standard enthalpy of formation of DEA at $298 \mathrm{~K}$ corrected with BACs and SOCs $(-71.8 \mathrm{~kJ} \mathrm{~mol}-1)$ corresponds well to the reported experimental value $\left(-72.5 \pm 1.2 \mathrm{~kJ} \mathrm{~mol}^{-1}\right)$. A complete list of the thermodynamic and kinetic parameters calculated in this work at the CBS-QB3 level of theory is provided in the Supporting Information.

\section{Kinetic model development}

A kinetic model is constructed for the pyrolysis and oxidation of DEA. This model consists of two parts, i.e. (1) a DEA kinetic model and (2) a kinetic model to account for the smallest species and the reactions between these species developed by Glarborg et al. [29] as a base mechanism.

The DEA kinetic model is generated automatically using the automatic kinetic model generation tool Genesys [28]. Starting from a number of initial species, a set of user-defined reaction families and constraints, this program automatically generates an elementary step kinetic model. Each reaction family specifies the rearrangement of bonds and atoms to go from the reactant(s) to the product(s) through the course of an elementary reaction. The thermodynamic consistency of the model is accounted for by implementing the reactions as reversible. To prevent the generation of kinetically insignificant species and reactions and hence limit the network size, the rule-based termination criterion is applied. Rules or constraints are specified to the reaction families and the 
product species. After the generation of the network, thermodynamic and kinetic parameters are assigned to all species and reactions. For this, Genesys is connected with user-defined databases containing species and reactions data from quantum chemical calculations. If available, entries from these databases are used. For DEA, quantum chemical calculations are performed for all the main species and reactions important to accurately describe the DEA chemistry, including the low-temperature oxidation chemistry. In case no ab initio thermodynamic data is available, Benson's group additivity method [39] is applied, for hydrocarbons [40,41], oxygenates [42] and nitrogen-containing compounds. In case no ab initio kinetic data is available, the group additivity method developed by Saeys et al. [43] and extended by Sabbe et al. [44-46] and Paraskevas et al. [47] is used. For reactions with a nitrogen atom in the reactive center, either in-house developed group additivity schemes or rate rules are used [48].

The automatically generated model for DEA is merged with the mechanism of Glarborg et al. [29]. This Glarborg et al. mechanism contains 150 species and 1397 reactions. It describes the chemistry of small hydrocarbons $\left(\mathrm{C}_{1}-\mathrm{C}_{2}\right)$ and nitrogen-containing species, including the formation and destruction of $\mathrm{NO}_{\mathrm{x}}$ in a combustion process. In the case that the same species or reactions appear in both the automatically generated Genesys mechanism and the Glarborg et al. mechanism, it is opted to retain the kinetic parameters from the Genesys mechanism. Several reactions in the Glarborg et al. mechanism important to accurately describe the DEA chemistry are approximated by analogy with hydrocarbon or oxygen-containing compounds. In the Genesys mechanism these reactions are at least based on similar reactions of nitrogen-containing compounds. In the Supporting Information a comparison is done between some rate coefficients in the Glarborg mechanism and calculated ab initio by Genesys. Not only do these rate coefficients differ several orders of magnitudes, also the relative importance of competing reactions is influenced. The complete kinetic model has 255 species and 2268 reactions and is available in the Supporting Information.

\section{Results}

\subsection{Quantum chemical calculations}

The decomposition of DEA during pyrolysis and oxidation is driven by free radical reactions. During pyrolysis, the formation of radicals is initiated by a homolytic bond scission. In case of oxidation, the initial radicals are formed via a hydrogen abstraction reaction by molecular oxygen. In Figure 1, the bond dissociation energies (BDE) of DEA are depicted. The two weakest bonds in DEA are the $\mathrm{C}_{\alpha}-\mathrm{C}_{\beta}$ and $\mathrm{C}_{\alpha}-\mathrm{N}$ bond. The presence of the amino group influences the BDE of nearby $\mathrm{C}-\mathrm{H}$ bonds compared to analogous alkanes. The BDEs of the $\mathrm{C}_{\alpha}-\mathrm{H}, \mathrm{C}_{\beta}-\mathrm{H}$ and $\mathrm{N}-\mathrm{H}$ bonds are equal to 381,421 and $388 \mathrm{~kJ} \mathrm{~mol}^{-1}$, respectively. For comparison, the BDEs of a primary and secondary $\mathrm{C}-\mathrm{H}$ bond of alkanes are approximately 423 and $411 \mathrm{~kJ} \mathrm{~mol}^{-1}$. Hence, due to the presence of the nitrogen atom, the BDE of the $\mathrm{C}_{\alpha}-\mathrm{H}$ is lowered by approximately $30 \mathrm{~kJ} \mathrm{~mol}^{-1}$. The $\mathrm{N}-\mathrm{H}$ bond strength decreases from the primary to the secondary amines, due to the ability of the alkyl group to stabilize the formed radical by hyper-conjugation. For example, the BDE of the $\mathrm{N}-\mathrm{H}$ bond in ethylamine is equal to $416 \mathrm{~kJ} \mathrm{~mol}^{-1}$, while the BDE of the $\mathrm{NH}$ bond in diethylamine is $388 \mathrm{~kJ} \mathrm{~mol}^{-1}$. The lowest barrier for hydrogen abstraction from DEA by molecular oxygen is that for abstraction from $\mathrm{C}_{\alpha}-\mathrm{H}$, i.e. $133 \mathrm{~kJ} \mathrm{~mol}^{-1}$. The barriers for hydrogen abstraction from $\mathrm{C}_{\beta}-\mathrm{H}$ and $\mathrm{N}-\mathrm{H}$ are equal to respectively 197 and $143 \mathrm{~kJ} \mathrm{~mol}^{-1}$. Hence, the oxidation of DEA will start at significantly lower temperatures compared to pyrolysis, due to the lower barrier of the main initiating reactions. 


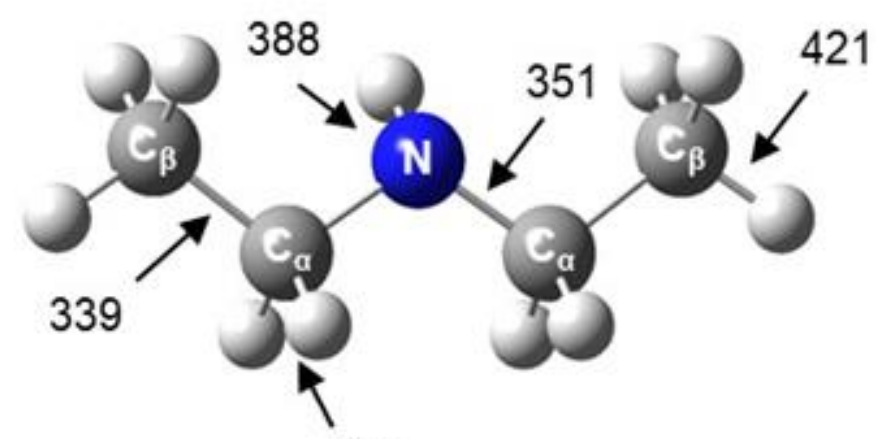

381

Figure 1. Bond dissociation energies (BDE), in $\mathrm{kJ} \mathrm{mol}^{-1}$, of diethylamine calculated at the CBS-QB3 level of theory.

Besides typical pyrolysis and oxidation radical reactions, an unimolecular decomposition reaction of diethylamine is possible, resulting in the formation of ethylamine and ethylene. This reaction is based on the elimination reaction of ethylamine, as reported by Almatarneh et al. [49]. The kinetic parameters for this unimolecular reaction are obtained from ab initio calculations with an activation energy equal to $281.9 \mathrm{~kJ} \mathrm{~mol}^{-1}$ and a pre-exponential factor of $3.7 \cdot 10^{11} \mathrm{~s}^{-1}$.

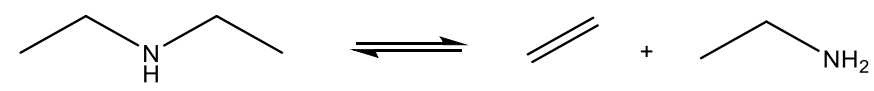

\subsection{Potential energy surface}

Alkylperoxy radicals (RO0•) can be formed after a barrierless reaction between the alkyl radicals and an oxygen molecule. To investigate the importance of this $\mathrm{O}_{2}$ addition in the oxidation of DEA, the potential energy surface is constructed for the addition of the radical formed after breaking of the weakest $\mathrm{C}-\mathrm{H}$ bond, i.e. CC・NCC, labeled $\mathrm{R}_{1}$, to an oxygen molecule. The relevant part of the potential energy surface is shown in Figure 2 . The addition of molecular oxygen to $R_{1}$ leads to the formation of the peroxide $\mathrm{R}_{1} \mathrm{OO}$. The corresponding reaction enthalpy is equal to $149 \mathrm{~kJ} \mathrm{~mol}^{-1}$, which is similar to the $\mathrm{C}-\mathrm{OO} \bullet$ bond strength of ethylperoxy radicals. The addition of molecular oxygen to the nitrogen-centered radical CC $\bullet$ NCC, i.e. the second most important radical, has an enthalpy of reaction of $33 \mathrm{~kJ} \mathrm{~mol}^{-1}$. As the transition states of consecutive reactions will most probably have a higher energy compared to the addition of $\mathrm{O}_{2}$, the formation of this alkylperoxy radical is ignored. Also, the $\mathrm{O}_{2}$ addition to the primary radical CC $\bullet \mathrm{NCC}$ is not considered, due to the lower importance of this radical as a result of the higher BDE of the $\mathrm{C}_{\beta}-\mathrm{H}$ bond.

The peroxide $\mathrm{R}_{1} \mathrm{OO}$ - can react further via different reaction pathways, including cylic ether formation and isomerization reactions. For the construction of the PES, only the isomerization reactions of $\mathrm{R}_{1} \mathrm{OO}$ - are considered, as these lead to the formation of product species which have been experimentally observed. In the first pathway a hydrogen atom migrates from $\mathrm{C}_{\alpha}$ to the peroxy group via a six-membered cyclic transition state, which is $84 \mathrm{~kJ} \mathrm{~mol}^{-1}$ higher in energy than $\mathrm{R}_{1}$ 00 • A subsequent $\beta$-scission leads to the formation of a hydroxyl radical, acetaldehyde and ethanimine $\left(\mathrm{CH}_{3}-\mathrm{CH}=\mathrm{NH}\right)$. The second path starts with an isomerization reaction via a threemembered cyclic transition state, which is $155 \mathrm{~kJ} \mathrm{~mol}^{-1}$ higher in energy than $\mathrm{R}_{1} \mathrm{O0} \bullet$. This path 
leads to the formation of ethylacetamide $\left(\mathrm{CH}_{3}-\mathrm{CH}_{2}-\mathrm{NH}-\mathrm{CO}-\mathrm{CH}_{3}\right)$ and a hydroxyl radical. The third possible isomerization reaction proceeds via a five-membered cyclic transition state, leading to a hydrogen abstraction from the nitrogen atom. The formed nitrogen-centered radical then undergoes a $\beta$-scission resulting in a methyl radical. As the transition states for these last two isomerization reactions have a higher energy compared to the addition of molecular oxygen to $R_{1}$, these reactions will most likely be less important compared to the first isomerization. At the applied experimental conditions, no low temperature reactivity is observed. For this reason, the second addition of molecular oxygen to the hydroperoxy radical leading to chain branching is omitted.

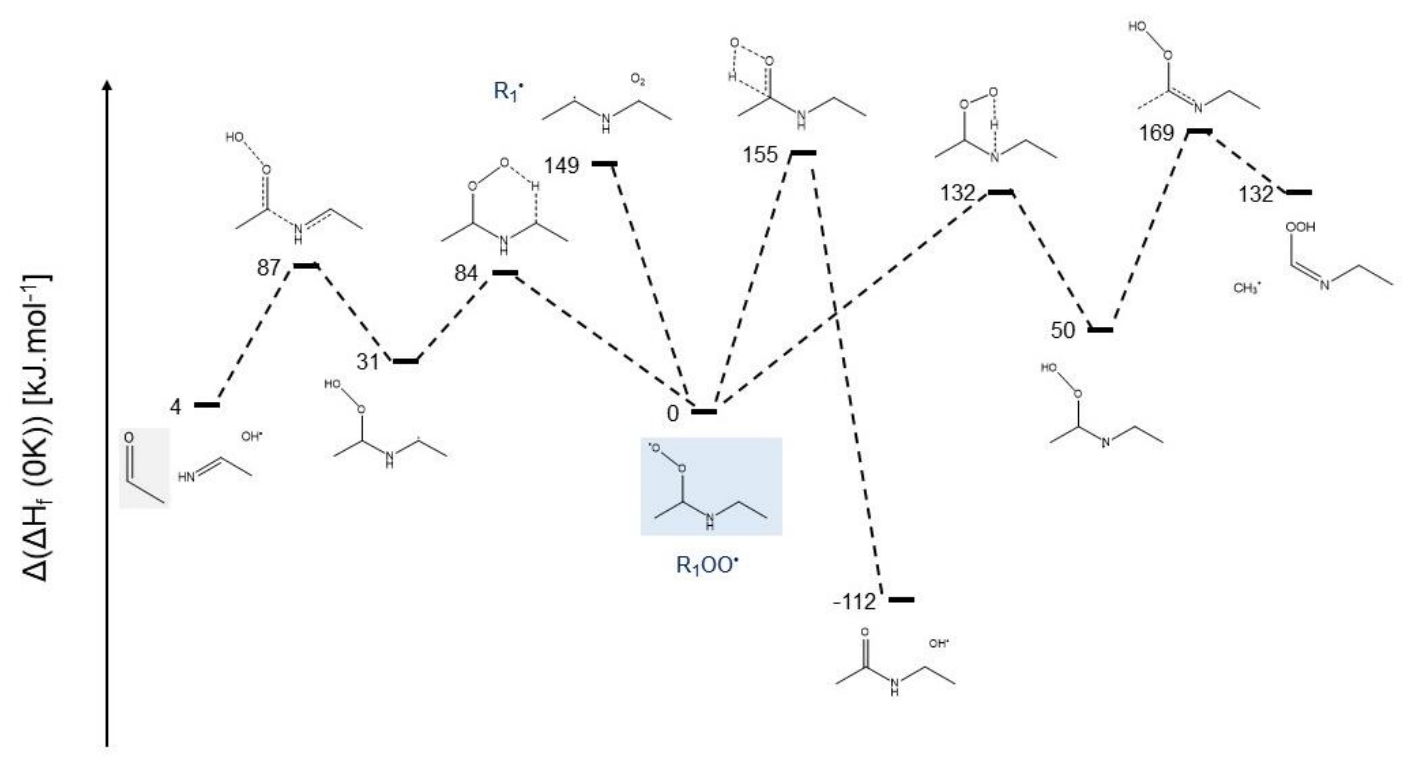

Figure 2. Selected part of the potential energy surface of the addition to molecular oxygen of the CC $\bullet$ NCC radical, i.e. the secondary radical formed after abstraction from the $\alpha$-carbon atom from DEA, labeled $R_{1}$. The values are CBS-QB3 calculated enthalpies of formation at $0 \mathrm{~K}$ relative to the enthalpy of formation of $\mathrm{R}_{1} \mathrm{OO} \bullet$.

\subsection{Experimental and kinetic modeling results}

Reactor simulations are performed with the new kinetic model using CHEMKIN [50]. The JSR is modelled as a continuously stirred tank reactor (CSTR) and the TR as a plug flow reactor (PFR) using the temperature profiles measured under unreactive conditions as input. These profiles as well as a discussion on the PFR assumption are provided in the Supporting Information. The results are discussed below, first for pyrolysis, next for oxidation.

\subsubsection{Pyrolysis}

Figure 3 presents the experimental and simulated mole fractions of DEA and the main product species as a function of temperature for the pyrolysis of DEA in both the JSR and TR units. Under pyrolysis conditions, DEA starts to convert around $800 \mathrm{~K}$ in both reactor units. The type of the reactor has an influence on the DEA conversion and this difference in reactivity is captured by the model. A faster conversion is achieved in the TR than in the JSR. Full conversion is reached at 950 $\mathrm{K}$ in the TR reactor and at $1000 \mathrm{~K}$ in the JSR. 

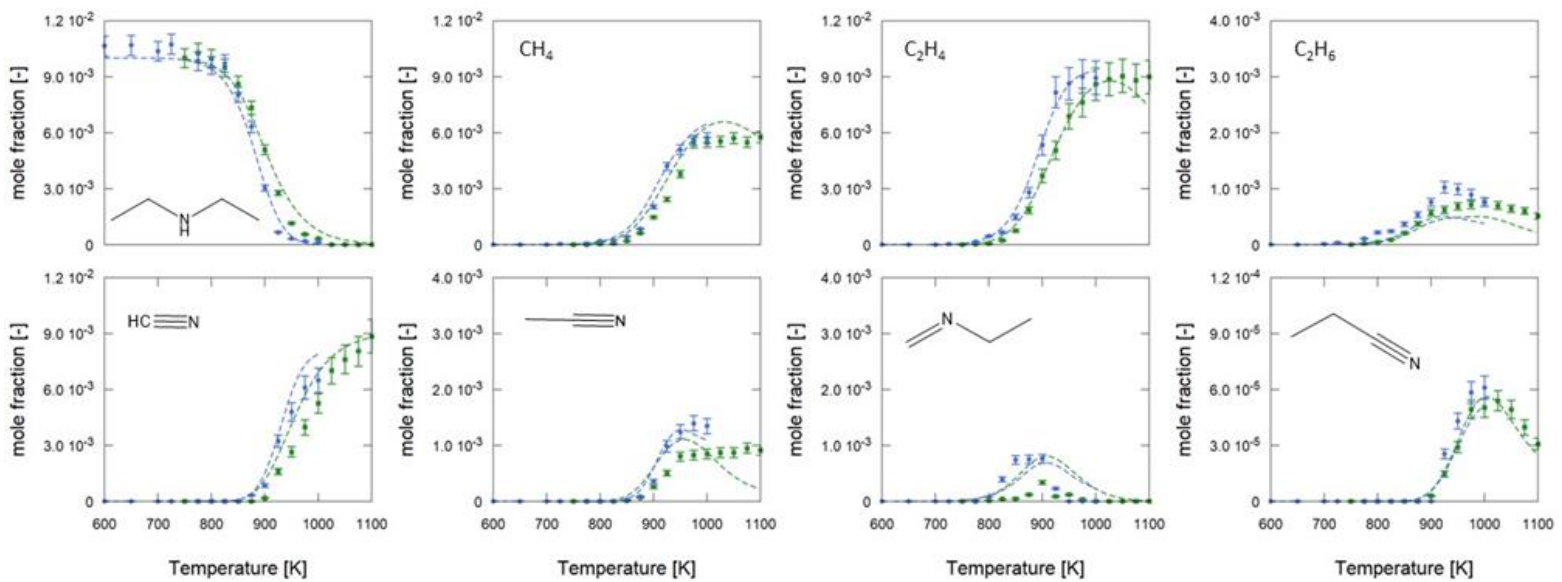

Figure 3. Species mole fractions as a function of temperature for the pyrolysis of DEA in the JSR (green) and the TR (blue). Experiment (symbols) and simulation results (lines) are compared. Experimental conditions are $2 \mathrm{~s}$ residence time, 1.07 bar and an inlet DEA mole fraction of 0.01 . (For interpretation of the references to color in this figure legend, the reader is referred to the web version of this article.)

The main hydrocarbon products observed are methane, ethene and ethane, while the main nitrogen-containing products are hydrogen cyanide, acetonitrile, propanenitrile and ethylmethanimine. Ethylmethanimine is one of the lowest temperature nitrogen-containing products that is formed. It is the smallest species containing an imine $(\mathrm{C}=\mathrm{N})$ group that is detected experimentally. Its mole fraction increases with temperature and reaches a maximum at $900 \mathrm{~K}$. The two main product species containing a nitrile group $(\mathrm{C} \equiv \mathrm{N})$ start to form at approximately 875 $\mathrm{K}$. In contrast to acetonitrile, the hydrogen cyanide mole fraction does not reach a maximum and its mole fraction keeps increasing even when full fuel conversion is reached. The formation of propanenitrile starts at a temperature approximately $25 \mathrm{~K}$ higher, and reaches a maximum at $1000 \mathrm{~K}$. Hydrogen cyanide is by far the major nitrogen-containing product and ethylene the main hydrocarbon product. Minor products species that are observed are propane, propene, 1-butene, 2-butene, butadiene, acrylonitrile and isobutyronitrile. There is almost no effect of the reactor type on the product distribution and product selectivity. In the TR, the formation of the products starts at a slightly lower temperature. In the intermediate temperature range, large recombination products are formed, containing at least five carbon atoms and two nitrogen atoms, and also an imine $(\mathrm{C}=\mathrm{N})$ or nitrile $(\mathrm{C} \equiv \mathrm{N})$ functional group. In the $\mathrm{TR}$ a lower number of recombination products are formed compared to the JSR.

\subsubsection{Oxidation}

Oxidation experiments of DEA are performed at fuel-rich, stoichiometric and fuel-lean conditions, corresponding to the equivalence ratios, $\varphi=2.0, \varphi=1.0$ and $\varphi=0.5$. The experimental results are depicted in Figures 4 to 6 respectively. The conversion of DEA starts at $600 \mathrm{~K}$, approximately 200 $\mathrm{K}$ lower compared to pyrolysis. The equivalence ratio does not have a significant influence on the conversion profile. The formation of acetaldehyde is observed at low temperatures, probably corresponding to the addition of molecular oxygen on the diethylamine radical, as discussed in Section 5.2. Furthermore, similar recombination products are formed in the JSR as during the pyrolysis of DEA. Oxidation products, which are not formed during the pyrolysis of DEA, include $\mathrm{CO}, \mathrm{CO}_{2}, \mathrm{~N}_{2}, \mathrm{NO}, \mathrm{NO}_{2}$ and nitromethane. 

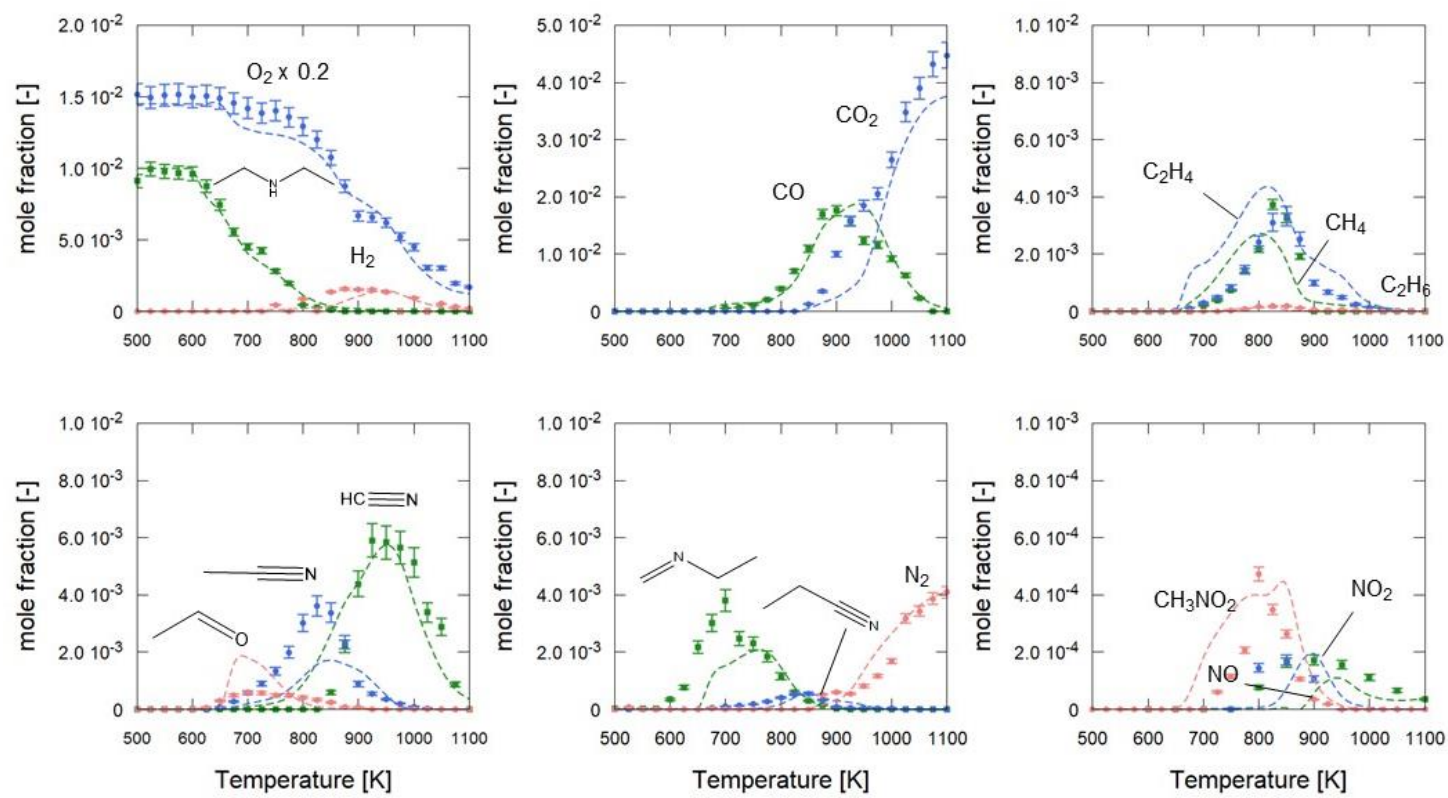

Figure 4. Species mole fractions as a function of temperature for the oxidation of DEA for an equivalence ratio of 1.0. Experiment (symbols) and simulation results (lines) are compared. Experimental conditions are $2 \mathrm{~s}$ residence time, 1.07 bar and an inlet mole fraction of DEA 0.01. The mole fractions of molecular oxygen for experimental points and simulations are divided by a factor 5 . The mole fractions of ethane for experimental points and simulations are multiplied by a factor 5 and for propanenitrile by a factor 10 .
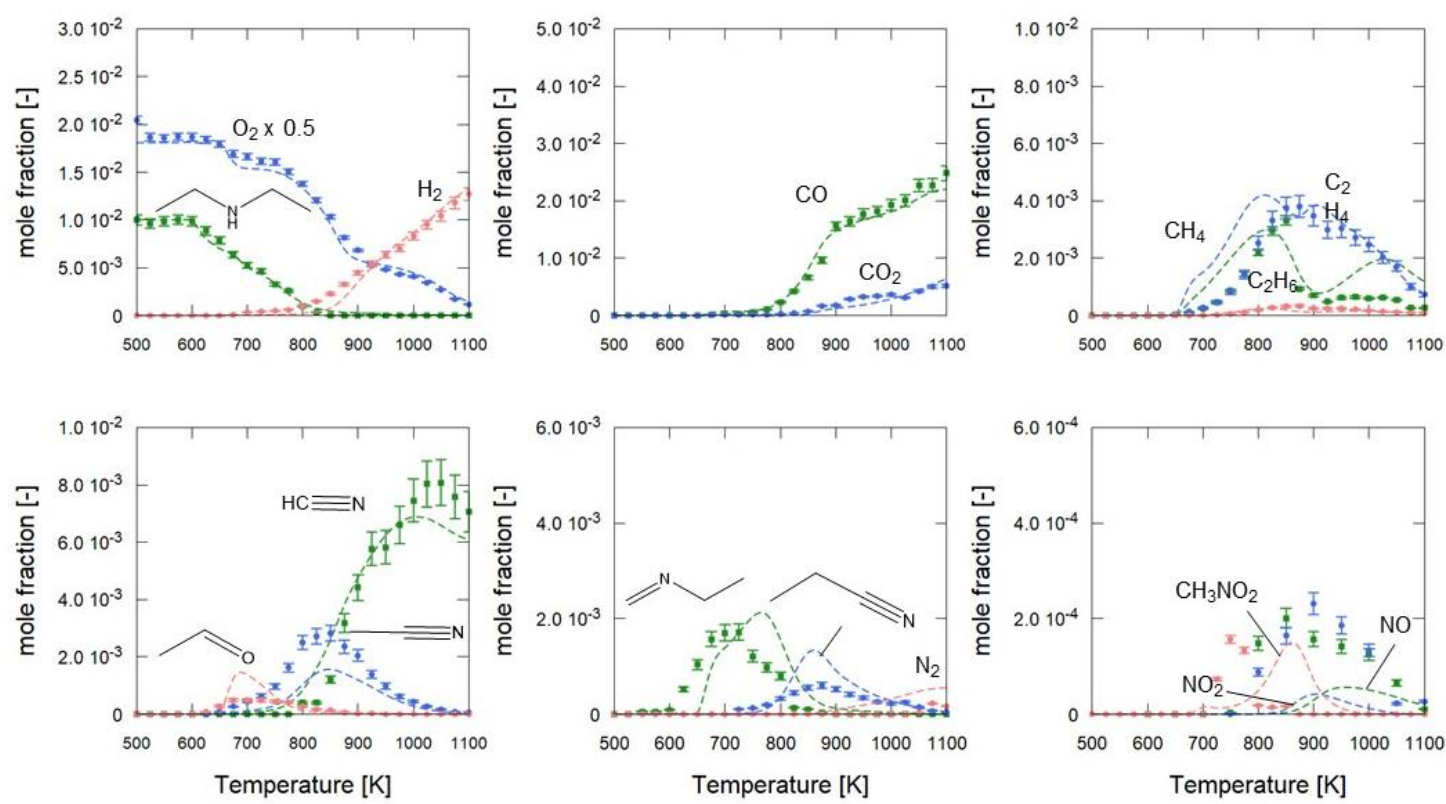

Figure 5. Species mole fractions as a function of temperature for the oxidation of DEA for an equivalence ratio of 2.0. Experiment (symbols) and simulation results (lines) are compared. Experimental conditions are $2 \mathrm{~s}$ residence time, 1.07 bar and an inlet mole fraction of DEA 0.01. The mole fractions of molecular oxygen for experimental points and simulations are divided by a factor 2 . The mole fractions of ethane for experimental points and simulations are multiplied by a factor 5 and for propanenitrile by a factor 10 . 
For $\varphi=1.0$ and 0.5 , the mole fraction of $\mathrm{CO}$ goes through a maximum indicating that $\mathrm{CO}$ is further oxidized to $\mathrm{CO}_{2}$. At fuel-rich conditions, $\mathrm{CO}$ keeps increasing with temperature and the mole fraction of $\mathrm{CO}_{2}$ is significantly less. The hydrocarbon mole fractions decrease when going from fuel-rich to fuel-lean conditions. Compared to pyrolysis, the maximum mole fractions of methane and ethylene are much lower. Overall, the new kinetic model succeeds in predicting the experimental trends. Large discrepancies are found for the methane and ethane. While for acetaldehyde the trend is captured by the model, it is clearly overpredicted.
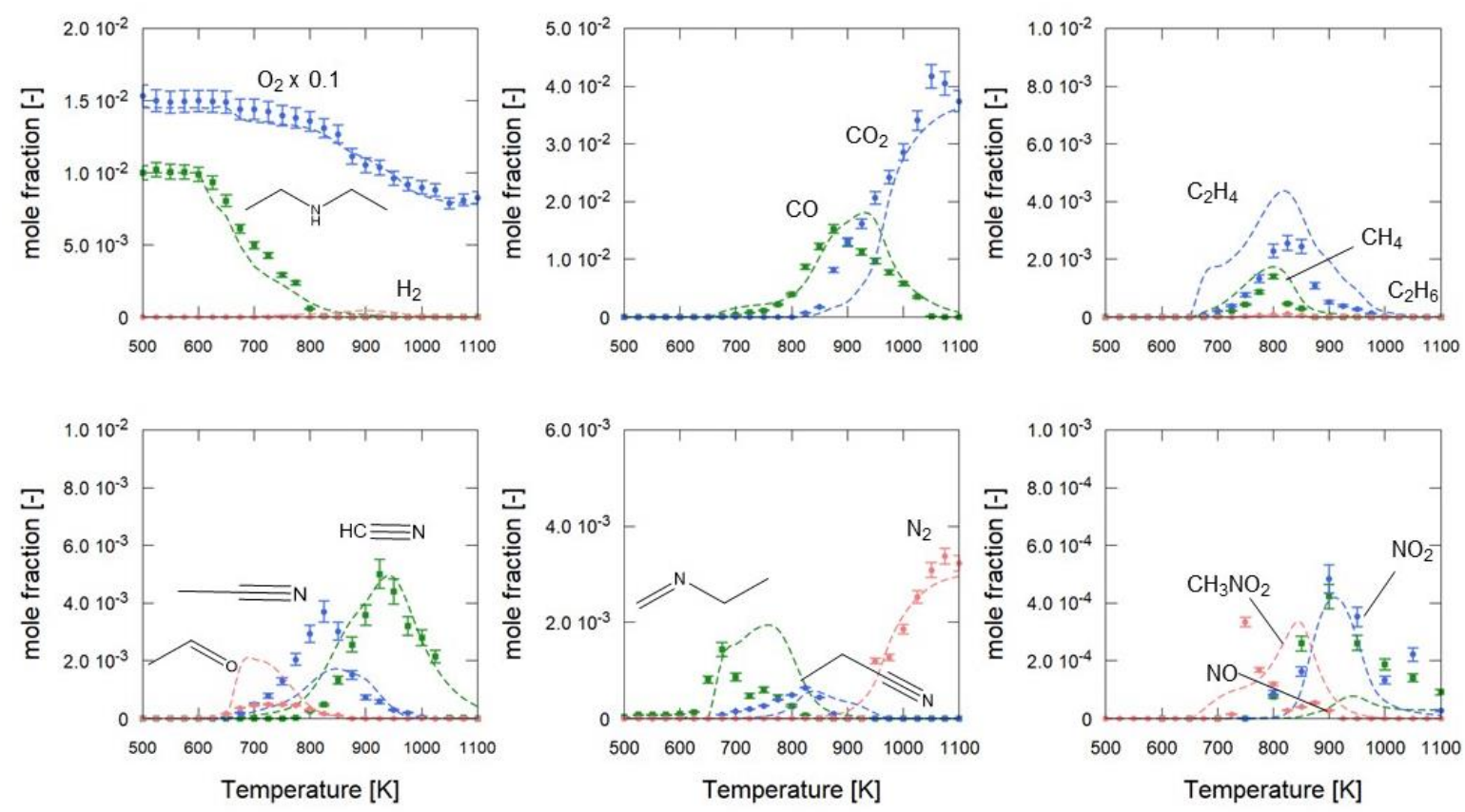

Figure 6. Species mole fractions as a function of temperature for the oxidation of DEA for an equivalence ratio of 0.5. Experiment (symbols) and simulation results (lines) are compared. Experimental conditions are $2 \mathrm{~s}$ residence time, $1.07 \mathrm{bar}$ and an inlet mole fraction of DEA 0.01 . The mole fractions of molecular oxygen for experimental points and simulations are divided by a factor 10. The mole fractions of ethane for experimental points and simulations are multiplied by a factor 5 and for propanenitrile by a factor 10 .

\section{Discussion}

\subsection{Pyrolysis}

A rate of production analysis for the pyrolysis of DEA at $900 \mathrm{~K}$ in the JSR is presented in Figure 7. Species that are detected experimentally are highlighted. At these experimental conditions, the DEA conversion is equal to $50 \%$. At $900 \mathrm{~K}$, DEA consumption is dominated by hydrogen abstractions. The contribution of both the homolytic scissions of the $\mathrm{C}-\mathrm{N}$ and $\mathrm{C}-\mathrm{C}$ bonds and the unimolecular elimination reaction $\left(\mathrm{R}_{1}\right)$ are small. The scissions, especially the $\mathrm{C}-\mathrm{N}$ scission, become more important at higher temperature and under pyrolysis conditions. In pyrolysis, the main abstracting species are the hydrogen atom and methyl radicals. Hydrogen abstraction from $\mathrm{C} \alpha$ is the main consumption channel. $\beta$-scission of the formed radical leads to the formation of ethanimine. Hydrogen abstraction from the $\mathrm{NH}$ bond in ethanimine dominates, as this is the most weakly bonded hydrogen atom. $\beta$-scission of the $\mathrm{C}-\mathrm{C}$ bond results in the formation of hydrogen cyanide, while $\mathrm{C}-\mathrm{H} \beta$-scission leads to acetonitrile. At $900 \mathrm{~K}$, this $\beta$-scission is the dominant 
formation pathway of hydrogen cyanide. Another important pathway for the formation of hydrogen cyanide proceeds via $\beta$-scission of the imine radical, formed from the ethylamine radical. This ethylamine radical is produced either via $\mathrm{C}-\mathrm{N}$ scission or hydrogen abstraction from the $\beta$-carbon atom followed by $\beta$-scission. This hydrogen cyanide formation pathway becomes more important at higher temperatures.

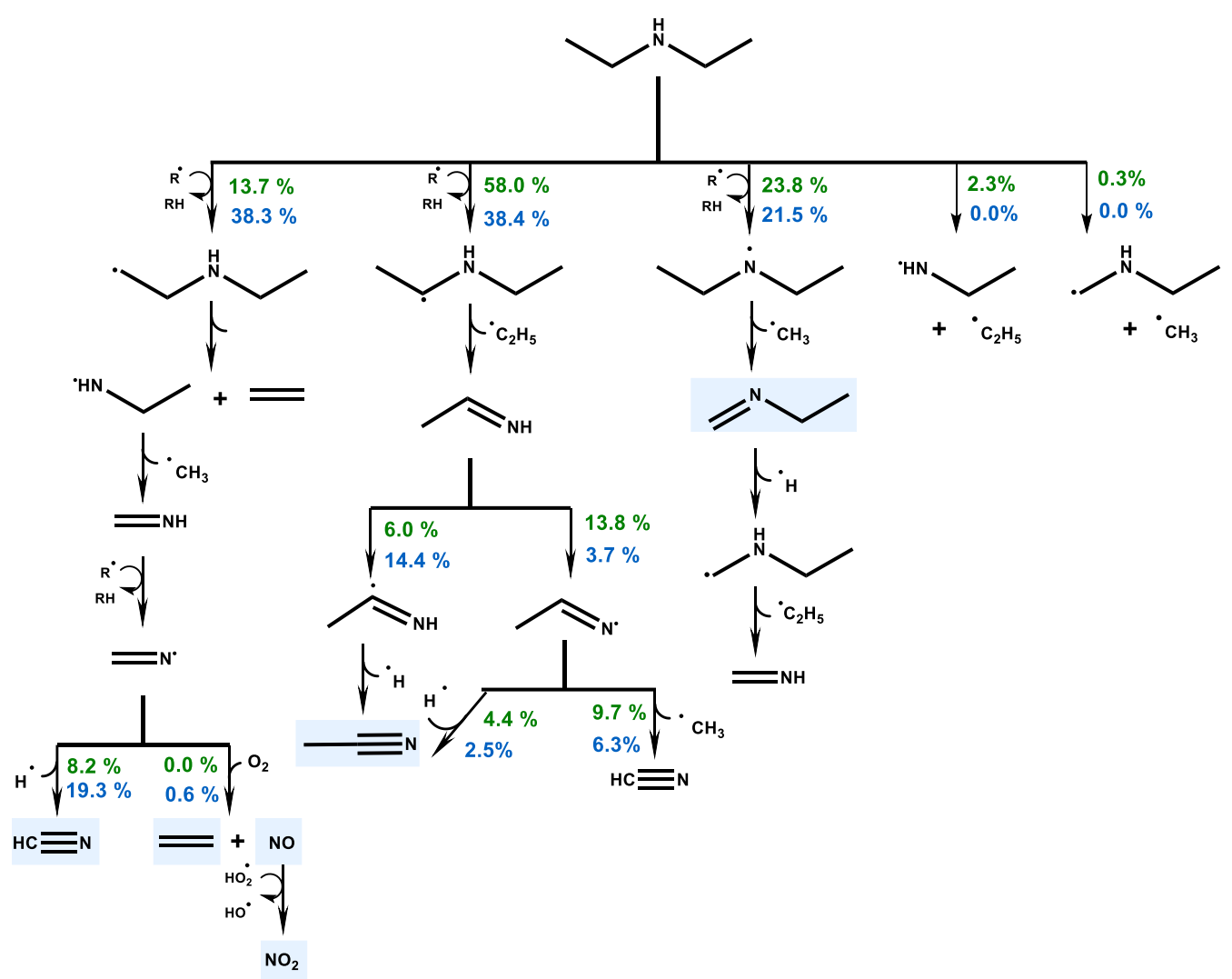

Figure 7. Rate of production analysis in the JSR for the pyrolysis and oxidation at intermediate temperatures. Percentages report the rate of productions relative to the total consumption of DEA at $900 \mathrm{~K}$ for pyrolysis (grey, underlined) and oxidation at $\varphi=2$ (black, italic). Species that are detected experimentally are highlighted.

\subsection{Oxidation at intermediate temperature}

The rate of production analysis for oxidation at fuel-rich conditions of DEA at $900 \mathrm{~K}$ is presented in Figure 7. At these experimental conditions, DEA is completely converted. Similar to pyrolysis, DEA consumption is dominated by hydrogen abstraction. In oxidation at fuel-rich conditions, the hydroxyl radicals and the hydrogen atoms are the main abstracting species. At $900 \mathrm{~K}$, the hydroperoxy radical is also an important abstracting radical, but its importance decreases at higher temperatures, because the $\mathrm{CN}$ scission starts to dominate favoring this reaction pathway.

Abstraction from $C_{\beta}$ is the main initiating reaction at $900 \mathrm{~K}$. At high temperatures, hydrogen cyanide and acrylonitrile start to decrease due to reaction with an oxygen atom forming the intermediate $\mathrm{NCO}$ species, which further leads to the formation of $\mathrm{CO}$ and subsequently $\mathrm{CO}_{2}$. The formation of $\mathrm{NO}$ starts at approximately $800 \mathrm{~K}$ via the reaction of the nitrogen-centered imine radical with molecular oxygen producing formaldehyde and NO. At this temperature, NO is immediately converted to $\mathrm{NO}_{2}$ via the reaction between $\mathrm{NO}$ and a hydroperoxy radical producing 
$\mathrm{NO}_{2}$ and a hydroxyl radical, causing a maximum of the mole fraction of $\mathrm{NO}_{2}$ at lower temperatures compared to NO. At $900 \mathrm{~K}, \mathrm{NO}_{2}$ is mainly formed via the reaction of NO with the hydroperoxy radical. By reaction with a hydrogen atom, it is converted back into NO. The balance between these two reactions is crucial for determination of the maximum of both the $\mathrm{NO}$ and $\mathrm{NO}_{2}$ mole fractions. For all three equivalence ratios, the simulated maxima of the $\mathrm{NO}$ and $\mathrm{NO}_{2}$ mole fractions are at 950 and $900 \mathrm{~K}$, respectively. From $900 \mathrm{~K}$, the formation of NO starts to be favored over $\mathrm{NO}_{2}$. This is not the case for oxidation at fuel-lean conditions, due to the higher concentration of hydroperoxy radicals leading to the oxidation of $\mathrm{NO}$ to $\mathrm{NO}_{2}$. At stoichiometric and fuel-lean conditions, $\mathrm{N}_{2}$ starts to form from the reaction between $\mathrm{CO}$ and $\mathrm{N}_{2} \mathrm{O}$. Minor production pathways include the reaction of $\mathrm{NO}$ with $\mathrm{NCO}$ and with an $\mathrm{NH}_{2}$ radical. These reactions become more important at higher temperatures. For the formation of $\mathrm{N}_{2}$, NCO seems to be a key species. Because this species is formed by reaction of hydrogen cyanide with an oxygen radical, $\mathrm{N}_{2}$ formation is negligible at fuel-rich conditions and the hydrogen cyanide mole fraction drops only slightly at higher temperatures. At stoichiometric and fuel-lean conditions, $\mathrm{N}_{2}$ is the main nitrogencontaining product at high temperatures.

\subsection{Oxidation at low temperature}

In Figure 8, the rate of production analysis is shown for the oxidation at stoichiometric conditions at a temperature of $700 \mathrm{~K}$. Under these experimental conditions, the conversion of DEA is equal to $47 \%$. The consumption of DEA proceeds completely via hydrogen abstraction. The main abstracting species are the hydroxyl and the hydroperoxy radical.

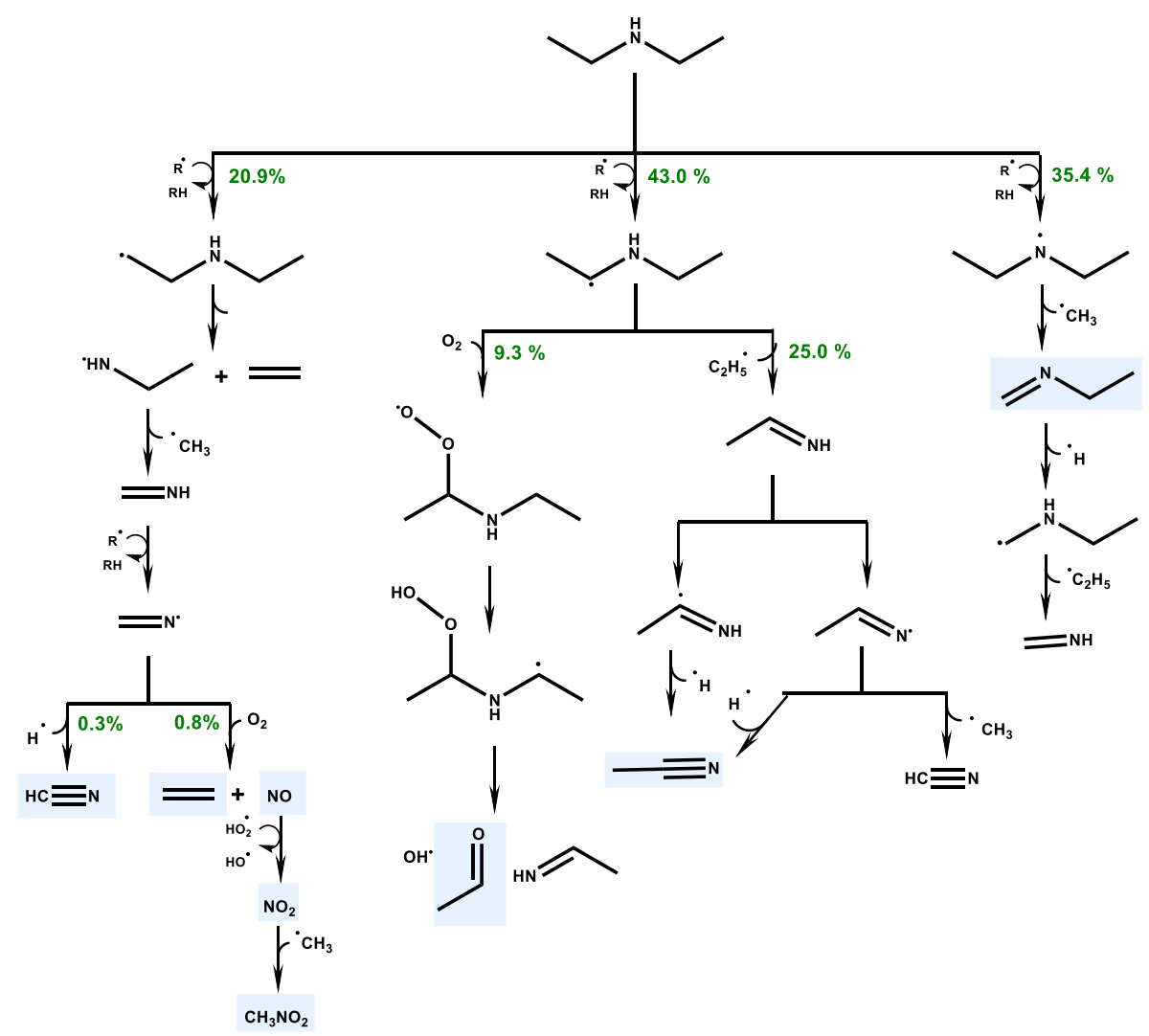

Figure 8. Rate of production analysis for the low-temperature oxidation at $\varphi=1$. Percentages report the rate of productions relative to the total consumption of DEA at $700 \mathrm{~K}$. Species that are detected experimentally are highlighted. 
Hydrogen abstraction from $\mathrm{C}_{\alpha}$ is favored. The formed radical can either undergo $\beta$-scission or addition to molecular oxygen. At $700 \mathrm{~K}$, the $\beta$-scission is more important compared to the addition to molecular oxygen. Addition to molecular oxygen leads to the formation of acetaldehyde after isomerization and $\beta$-scission, as discussed in Section 5.2. With increasing temperature, this $\beta$-scission becomes even more favored and the addition of molecular oxygen cannot compete anymore. $\mathrm{NO}_{2}$ combines with a methyl radical leading to the formation of nitromethane. Sensitivity analyses are performed to study the decomposition of DEA during pyrolysis and oxidation $(\varphi=1.0)$ at different temperatures and the formation of the main pollutants $\mathrm{NO}, \mathrm{NO}_{2}$ and $\mathrm{CH}_{3} \mathrm{NO}_{2}$ at $900 \mathrm{~K}$ and $\varphi=1.0$. Detailed results are given in the Supporting Information. The most sensitive reactions for the decomposition of DEA in both pyrolysis and oxidation are those directly related to DEA decomposition by homolytic scissions and hydrogen abstraction reactions and those that increase the number of radicals and hence the reactivity, e.g. recombination of methyl radicals for pyrolysis and recombination of hydroperoxy radicals for oxidation. The formation of NO is sensitive to reactions involving the imine radical. The reaction of this radical with molecular oxygen is the main production pathway of NO.

\section{Conclusions}

The pyrolysis of DEA is studied using two different reactor units, i.e. a jet-stirred reactor and a tubular reactor. The main nitrogen-containing products from the pyrolysis of DEA are hydrogen cyanide, acetonitrile and other species containing a nitrile (CN) group. These are formed via intermediate species containing an imine $(\mathrm{CN})$ bond. Oxidation experiments are performed at three different equivalence ratios, i.e. $\varphi=1.0,2.0$ and 0.5 in a jet-stirred reactor. In oxidation, the formation of $\mathrm{NO}$ and $\mathrm{NO}_{2}$ competes with hydrogen cyanide formation, as these are all formed via the same important intermediate: methanimine radical. Other important oxidation products, not detected during pyrolysis, include nitromethane, acetaldehyde and $\mathrm{N}_{2}$. During both the pyrolysis and oxidation of DEA, large recombination products are formed, containing at least five carbon atoms and two nitrogen atoms, and also an imine (CN) or nitrile (CN) functional group. The elementary step kinetic model for DEA pyrolysis and oxidation, with the important thermodynamic and kinetic parameters obtained from quantum chemical calculations, can without any manual adjustment represent both datasets.

\section{Acknowledgements}

The computational resources and services used in this work were provided by the VSC (Flemish Supercomputer Center), funded by the Research Foundation - Flanders (FWO) and the Flemish Government - department EWI. Cato A.R. Pappijn acknowledges financial support from a doctoral fellowship from the Research Foundation - Flanders (FWO). The authors also would like to acknowledge the financial support from the European Research Council under the European Union's Horizon 2020 research and innovation program (ERC grant agreement no.818607), COST Action CM1404 "Chemistry of Smart Energy Carriers and Technologies" (SMARTCATS) and the IMPROOF project (H2020-IND-CE-2016-17/H2020-SPIRE-2016) under European Union's Horizon 2020 research and innovation program (grant agreement no.723706). The work on pyrolysis experiments in tubular reactor has been supported by Terbis, a French company. 


\section{Supplementary material}

- A Word document with supporting information

- A spreadsheet with experimental data

- A file containing the detailed kinetic model

\section{References}

[1] H.E. Toraman, K. Franz, F. Ronsse, K.M. Van Geem, G.B. Marin, Quantitative analysis of nitrogen containing compounds in microalgae based bio-oils using comprehensive two-dimensional gaschromatography coupled to nitrogen chemiluminescence detector and time of flight mass spectrometer, Journal of chromatography. A, 1460 (2016) 135-146.

[2] A. Williams, J.M. Jones, L. Ma, M. Pourkashanian, Pollutants from the combustion of solid biomass fuels, Progress in Energy and Combustion Science, 38 (2012) 113-137.

[3] J.A. Miller, C.T. Bowman, Mechanism and modeling of nitrogen chemistry in combustion, Progress in Energy and Combustion Science, 15 (1989) 287-338.

[4] A.M. Dean, J.W. Bozzelli, Combustion Chemistry of Nitrogen, in: W.C. Gardiner (Ed.) Gas-Phase Combustion Chemistry, Springer New York, New York, NY, 2000, pp. 125-341.

[5] G. Chiavari, G.C. Galletti, Pyrolysis-gas chromatography/mass spectrometry of amino acids, J. Anal. Appl. Pyrolysis, 24 (1992) 123-137.

[6] R.K. Sharma, W.G. Chan, J. Wang, B.E. Waymack, J.B. Wooten, J.I. Seeman, M.R. Hajaligol, On the role of peptides in the pyrolysis of amino acids, J. Anal. Appl. Pyrolysis, 72 (2004) 153-163.

[7] Z. Tian, Y. Li, T. Zhang, A. Zhu, F. Qi, Identification of Combustion Intermediates in Low-Pressure Premixed Pyridine/Oxygen/Argon Flames, The Journal of Physical Chemistry A, 112 (2008) 13549-13555.

[8] N. R. Hore, D. K. Russell, Radical pathways in the thermal decomposition of pyridine and diazines: a laser pyrolysis and semi-empirical study, Journal of the Chemical Society, Perkin Transactions 2, (1998) 269-276. [9] J.C. Mackie, M.B. Colket, P.F. Nelson, Shock tube pyrolysis of pyridine, The Journal of Physical Chemistry, 94 (1990) 4099-4106.

[10] E. Ikeda, P. Nicholls, J.C. Mackie, A kinetic study of the oxidation of pyridine, Proceedings of the Combustion Institute, 28 (2000) 1709-1716.

[11] T.J. Houser, M. Hull, R.M. Alway, T. Biftu, Kinetics of formation of HCN during pyridine pyrolysis, Int. J. Chem. Kinet., 12 (1980) 569-574.

[12] L. Zhai, X. Zhou, R. Liu, A Theoretical Study of Pyrolysis Mechanisms of Pyrrole, The Journal of Physical Chemistry A, 103 (1999) 3917-3922.

[13] Z. Tian, Y. Li, T. Zhang, A. Zhu, Z. Cui, F. Qi, An experimental study of low-pressure premixed pyrrole/oxygen/argon flames with tunable synchrotron photoionization, Combustion and Flame, 151 (2007) 347-365.

[14] J.C. Mackie, M.B. Colket, P.F. Nelson, M. Esler, Shock tube pyrolysis of pyrrole and kinetic modeling, International Journal of Chemical Kinetics, 23 (1991) 733-760.

[15] X. Hong, L. Zhang, T. Zhang, F. Qi, An Experimental and Theoretical Study of Pyrrole Pyrolysis with Tunable Synchrotron VUV Photoionization and Molecular-Beam Mass Spectrometry, The Journal of Physical Chemistry A, 113 (2009) 5397-5405.

[16] G.B. Bacskay, M. Martoprawiro, J.C. Mackie, The thermal decomposition of pyrrole: an ab initio quantum chemical study of the potential energy surface associated with the hydrogen cyanide plus propyne channel, Chemical Physics Letters, 300 (1999) 321-330.

[17] B. Zheng, X. Li, L. Guo, Investigation of N behavior during coal pyrolysis and oxidation using ReaxFF molecular dynamics, Fuel, 233 (2018) 867-876.

[18] L. Zhang, S. Dagen, M. Zhong, The effect of functinal forms of nitrogen on fuel- $\mathrm{NO}_{\mathrm{x}}$ emissions Environ Monit Assess, 187 (2014) 4196

[19] X. Liu, Z. Luo, C. Yu, B. Jin, H. Tu, Release mechanism of Fuel-N into $\mathrm{NO}_{x}$ and $\mathrm{N}_{2} \mathrm{O}$ Precursors during pyrolysis of rice straw energies, Energies 11 (2018) 520 
[20] R.P. Lindstedt, F.C. Lockwood, M.A. Selim, Detailed Kinetic Modelling of Chemistry and Temperature Effects on Ammonia Oxidation, Combustion Science and Technology, 99 (1994) 253-276.

[21] O. Mathieu, E.L. Petersen, Experimental and modeling study on the high-temperature oxidation of Ammonia and related $\mathrm{NO}_{\mathrm{x}}$ chemistry, Combustion and Flame, 162 (2015) 554-570.

[22] C. Duynslaegher, F. Contino, J. Vandooren, H. Jeanmart, Modeling of ammonia combustion at low pressure, Combustion and Flame, 159 (2012) 2799-2805.

[23] D.F. Davidson, K. Kohse-Höinghaus, A.Y. Chang, R.K. Hanson, A pyrolysis mechanism for ammonia, Int. J. Chem. Kinet., 22 (1990) 513-535.

[24] M.V. Kantak, K.S. De Manrique, R.H. Aglave, R.P. Hesketh, Methylamine oxidation in a flow reactor: Mechanism and modeling, Combustion and Flame, 108 (1997) 235-265.

[25] M. Votsmeier, S. Song, D.F. Davidson, R.K. Hanson, Shock tube study of monomethylamine thermal decomposition and NH2 high temperature absorption coefficient, Int. J. Chem. Kinet., 31 (1999) 323-330.

[26] A. Lucassen, K. Zhang, J. Warkentin, K. Moshammer, P. Glarborg, P. Marshall, K. Kohse-Höinghaus, Fuelnitrogen conversion in the combustion of small amines using dimethylamine and ethylamine as biomassrelated model fuels, Combustion and Flame, 159 (2012) 2254-2279.

[27] S. Li, D.F. Davidson, R.K. Hanson, Shock tube study of ethylamine pyrolysis and oxidation, Combustion and Flame, 161 (2014) 2512-2518.

[28] N.M. Vandewiele, K.M. Van Geem, M.F. Reyniers, G.B. Marin, Genesys: Kinetic model construction using chemo-informatics, Chem. Eng. J., 207 (2012) 526-538.

[29] P. Glarborg, J.A. Miller, B. Ruscic, S.J. Klippenstein, Modeling nitrogen chemistry in combustion, Progress in Energy and Combustion Science, 67 (2018) 31-68.

[30] O. Herbinet, F. Battin-Leclerc, Progress in Understanding Low-Temperature Organic Compound Oxidation Using a Jet-Stirred Reactor, Int. J. Chem. Kinet., 46 (2014) 619-639.

[31] N. Vin, F. Battin-Leclerc, O. Herbinet, A study of thermal decomposition of bromoethane, J. Anal. Appl. Pyrolysis, 136 (2018) 199-207.

[32] J.A.M. Jr., M.J. Frisch, J.W. Ochterski, G.A. Petersson, A complete basis set model chemistry. VI. Use of density functional geometries and frequencies, The Journal of Chemical Physics, 110 (1999) 2822-2827.

[33] M.J. Frisch, G.W. Trucks, H.B. Schlegel, G.E. Scuseria, M.A. Robb, J.R. Cheeseman, G. Scalmani, V. Barone, G.A. Petersson, H. Nakatsuji, X. Li, M. Caricato, A.V. Marenich, J. Bloino, B.G. Janesko, R. Gomperts, B. Mennucci, H.P. Hratchian, J.V. Ortiz, A.F. Izmaylov, J.L. Sonnenberg, Williams, F. Ding, F. Lipparini, F. Egidi, J. Goings, B. Peng, A. Petrone, T. Henderson, D. Ranasinghe, V.G. Zakrzewski, J. Gao, N. Rega, G. Zheng, W. Liang, M. Hada, M. Ehara, K. Toyota, R. Fukuda, J. Hasegawa, M. Ishida, T. Nakajima, Y. Honda, O. Kitao, H. Nakai, T. Vreven, K. Throssell, J.A. Montgomery Jr., J.E. Peralta, F. Ogliaro, M.J. Bearpark, J.J. Heyd, E.N. Brothers, K.N. Kudin, V.N. Staroverov, T.A. Keith, R. Kobayashi, J. Normand, K. Raghavachari, A.P. Rendell, J.C. Burant, S.S. Iyengar, J. Tomasi, M. Cossi, J.M. Millam, M. Klene, C. Adamo, R. Cammi, J.W. Ochterski, R.L. Martin, K. Morokuma, O. Farkas, J.B. Foresman, D.J. Fox, Gaussian 16 Rev. B.01, in, Wallingford, CT, 2016.

[34] R. Van de Vijver, K.M. Van Geem, G.B. Marin, On-the-fly ab initio calculations toward accurate rate coefficients, Proceedings of the Combustion Institute, 37 (2019) 283-290.

[35] A.L.L. East, L. Radom, Ab initio statistical thermodynamical models for the computation of third-law entropies, The Journal of Chemical Physics, 106 (1997) 6655-6674.

[36] L.A. Curtiss, K. Raghavachari, P.C. Redfern, J.A. Pople, Assessment of Gaussian-2 and density functional theories for the computation of enthalpies of formation, The Journal of Chemical Physics, 106 (1997) 10631079.

[37] G.A. Petersson, D.K. Malick, W.G. Wilson, J.W. Ochterski, J.A.M. Jr., M.J. Frisch, Calibration and comparison of the Gaussian-2, complete basis set, and density functional methods for computational thermochemistry, The Journal of Chemical Physics, 109 (1998) 10570-10579.

[38] C. Eckart, The Penetration of a Potential Barrier by Electrons, Physical Review, 35 (1930) 1303-1309. [39] S.W. Benson, F.R. Cruickshank, D.M. Golden, G.R. Haugen, H.E. O'Neal, A.S. Rodgers, R. Shaw, R. Walsh, Additivity rules for the estimation of thermochemical properties, Chemical Reviews, 69 (1969) 279-324.

[40] M.K. Sabbe, M. Saeys, M.F. Reyniers, G.B. Marin, V. Van Speybroeck, M. Waroquier, Group additive values for the gas phase standard enthalpy of formation of hydrocarbons and hydrocarbon radicals, J. Phys. Chem. A, 109 (2005) 7466-7480. 
[41] M.K. Sabbe, F. De Vleeschouwer, M.-F. Reyniers, M. Waroquier, G.B. Marin, First Principles Based Group Additive Values for the Gas Phase Standard Entropy and Heat Capacity of Hydrocarbons and Hydrocarbon Radicals, The Journal of Physical Chemistry A, 112 (2008) 12235-12251.

[42] P.D. Paraskevas, M.K. Sabbe, M.F. Reyniers, N. Papayannakos, G.B. Marin, Group additive values for the gas-phase standard enthalpy of formation, entropy and heat capacity of oxygenates, Chemistry (Weinheim an der Bergstrasse, Germany), 19 (2013) 16431-16452.

[43] M. Saeys, M.F. Reyniers, G.B. Marin, V. Van Speybroeck, M. Waroquier, Ab initio group contribution method for activation energies for radical additions, Aiche J., 50 (2004) 426-444.

[44] M.K. Sabbe, A.G. Vandeputte, M.-F. Reyniers, M. Waroquier, G.B. Marin, Modeling the influence of resonance stabilization on the kinetics of hydrogen abstractions, Physical Chemistry Chemical Physics, 12 (2010) 1278-1298.

[45] M.K. Sabbe, M.F. Reyniers, V. Van Speybroeck, M. Waroquier, G.B. Marin, Carbon-Centered Radical Addition and $\beta$-Scission Reactions: Modeling of Activation Energies and Pre-exponential Factors, ChemPhysChem, 9 (2008) 124-140.

[46] M.K. Sabbe, M.-F. Reyniers, M. Waroquier, G.B. Marin, Hydrogen Radical Additions to Unsaturated Hydrocarbons and the Reverse $\beta$-Scission Reactions: Modeling of Activation Energies and Pre-Exponential Factors, ChemPhysChem, 11 (2010) 195-210.

[47] P.D. Paraskevas, M.K. Sabbe, M.-F. Reyniers, G.B. Marin, N.G. Papayannakos, Group additive kinetic modeling for carbon-centered radical addition to oxygenates and $\beta$-scission of oxygenates, Aiche J, 62 (2016) 802-814.

[48] L. Cai, H. Pitsch, S.Y. Mohamed, V. Raman, J. Bugler, H. Curran, S.M. Sarathy, Optimized reaction mechanism rate rules for ignition of normal alkanes, Combust Flame, 173 (2016) 468-482.

[49] M.H. Almatarneh, M. Altarawneh, R.A. Poirier, I.A. Saraireh, High level ab initio, DFT, and RRKM calculations for the unimolecular decomposition reaction of ethylamine, J Comput Sci, 5 (2014) 568-575.

[50] R. Kee, F. Rupley, J. Miller, M. Coltrin, J. Grcar, E. Meeks, H. Moffat, A. Lutz, G. Dixon-Lewis, M. Smooke, CHEMKIN-PRO in, Reaction Design Inc, San Diego (CA), 2010. 